\title{
A relação entre tecnologias sociais e economia solidária: um estudo de caso em uma cooperativa de catadores de resíduos
}

Rafaela Francisconi Gutierrez.

Doutoranda do Programa de Pós-Graduação em Política Científica e Tecnológica da Universidade Estadual de Campinas (UNICAMP)

Maria Zanin

Programa de Pós-Graduação em Ciência, Tecnologia e Sociedade da Universidade Federal de São Carlos (UFSCar)

Recebido: 31/10/2012 Versão revisada (entregue): 22/03/2013 Aprovado: 01/04/2013

\begin{abstract}
Resumo
As cooperativas de catadores de resíduos sólidos são empreendimentos, que por serem organizadas e realizadas solidariamente por seus trabalhadores e trabalhadoras, de forma coletiva e autogestionária, fazem parte do que se denomina, no Brasil, de Economia Solidária. Este trabalho tem por objetivo identificar aspectos da relação entre as tecnologias existentes nestas cooperativas e os valores da economia solidária. Para isto foi estudado o estágio atual de desenvolvimento de uma cooperativa de catadores, situada no município de São Carlos/SP, considerando os seguintes aspectos: processo de coleta, triagem e comercialização; organização do trabalho; tecnologias utilizadas e desenvolvidas e os apoios e parcerias existentes. Para a coleta de dados foi utilizada a técnica observacional e de entrevistas. Como resultado foi observado que os cooperados se apropriaram das tecnologias existentes. Quanto aos aspectos da economia solidária, eles possuem a propriedade coletiva dos meios de produção e fazem a gestão da cooperativa; não há divisão técnica do trabalho: todos os sócios aprendem e são capazes de exercer as diferentes atividades dentro da cooperativa; e os conhecimentos necessários para o desenvolvimento das atividades são transmitidos entre os cooperados.
\end{abstract}

Palavras-chave | Adequação sócio-técnica; catadores de resíduos; cooperativas; economia solidária; tecnologias sociais.

Código JEL | J21; 032; P13.

\section{THE RELATIONSHIP BETWEEN SOCIAL TECHNOLOGIES AND SOLIDARITY ECONOMY: A CASE STUDY IN COOPERATIVE OF WASTE PICKERS}

\begin{abstract}
The cooperatives of recyclable solid waste projects, which are organized and conducted jointly by their workers, in a self-managed and collectively way, are part of what is called in Brazil, Solidarity Economy. This study aims at identifying aspects of the relationship between the
\end{abstract}


existing technologies in these cooperatives and the values of solidarity economy. In order to do so we have studied the current stage of development of a cooperative of waste pickers, located in São Carlos / SP, considering the following aspects: the process of collecting, sorting out and marketing, the organization of work, technologies used and developed and the existing support programs and partnerships. For the data collection the technique used was observation and interviews. As a result we observed that the cooperative members utilized existing technologies. In regards to the solidarity economy, they have collective ownership of the means of production and manage the cooperative, and there is no technical division of labor: all members are able to learn and perform different activities within the cooperative, and the necessary knowledge for the development of activities which are transmitted among the members.

Keywords | Socio-technical adequacy; waste pickers; cooperatives, solidarity economy, social technologies.

JEL-Code | J21; 032; P13.

\section{LA RELACIÓN ENTRE TECNOLOGÍAS SOCIALES Y ECONOMÍA SOLIDARIA: UN ESTUDIO DE CASO EN UNA COOPERATIVA DE RECOLECTORES DE RESIDUOS}

\section{Resumen}

Las cooperativas de recolectores de residuos sólidos son emprendimientos que organizan colectivamente trabajadores y trabajadoras de forma autogestionaria y pertenecen a lo que en Brasil se denomina Economía Solidaria. Este estudio tiene como objetivo identificar los aspectos de la relación entre las tecnologías existentes en estas cooperativas y los valores de la economía solidaria. Para ello se estudió el estado actual de desarrollo de una cooperativa de recolectores de residuos, ubicada en São Carlos / SP, teniendo en cuenta los siguientes aspectos: el proceso de recolección, clasificación y comercialización; organización del trabajo; tecnologías utilizadas y desarrolladas; y los apoyos y vínculos de cooperación existentes. Los datos fueron obtenidos a través de observación y entrevistas. Como resultado se constató que los cooperados de apropiaron de las tecnologías existentes. En lo que respecta a la economía solidaria, cuentan con la propiedad colectiva de los medios de producción y desarrollan la gestión de la cooperativa sin división técnica del trabajo: todos los miembros son capaces de aprender y realizar las diferentes actividades dentro de la cooperativa y los conocimientos necesarios para éstas son transmitidos entre los miembros.

Palabras-clave | Adecuación socio-técnica; recolectores de residuos; cooperativas; economía solidaria; tecnologías sociales.

Código JEL | J21; 032; P13.

\section{Introdução ${ }^{1}$}

No Brasil, as cooperativas de trabalhadores e trabalhadoras do setor de reciclagem

\footnotetext{
${ }^{1}$ Este artigo baseia-se em trabalho apresentado nas IX Jornadas Latinoamericanas de Estudios Sociales de la Ciencia y la Tecnología-ESOCITE, realizadas no México em 2012.
} 
de resíduos domiciliares são empreendimentos recentes que, normalmente, são criados de modo informal por parte de seus associados e, posteriormente, ao receberem apoio de instituições se formalizam em cooperativas ou associações. Este tipo de empreendimento organizado e realizado solidariamente por trabalhadores e trabalhadoras sob a forma coletiva e autogestionária faz parte do que estamos denominando no Brasil de Economia Solidária. Esta economia tem sido considerada nas últimas décadas como uma nova forma de organização econômica social, mais humanizadora, onde o homem é valorizado como ser humano e não mais como uma mercadoria, reduzido apenas à capacidade de trabalho e à disposição dos que dirigem o ciclo vicioso do capitalismo neoliberal globalizado, que traz em sua raiz a contínua exploração do ser humano.

Os empreendimentos solidários recebem apoio de diferentes entidades brasileiras, tais como: ONGs, OSCIPs, Igrejas, Movimento Sindical (Central, Sindicato, Federação), Cooperativas de Créditos, Universidades, incubadoras universitárias como a rede de ITCPs (Incubadores Tecnológicas de Cooperativas Populares) e a Unitrabalho e órgãos governamentais (principalmente a Secretaria de Economia Solidária do Ministério do Trabalho e Empregos - SENAES/MTE). Essas entidades de assessoria, apoio e fomento à Economia Solidária são organizações que amparam os empreendimentos econômicos solidários em diversos setores, tais como: capacitação, incubação, assessoria, acompanhamento e assistência técnica e organizativa (BRASIL, 2007).

De acordo com o mapeamento do Atlas da Economia Solidária (BRASIL, 2007) foram identificados 21.859 empreendimentos solidários nos diferentes tipos de atividades econômicas (produção, serviços, distribuição, poupança, crédito, etc), dos quais 506 são empreendimentos de serviços de coleta e triagem de resíduos. No Estado de São Paulo foram identificados 115, com a participação de mais de 3000 catadores organizados (GUTIERREZ; ZANIN, 2011a).

Estes empreendimentos econômicos solidários (EES) de catadores de resíduos sólidos estão sendo criados em diversos municípios brasileiros como uma alternativa para a humanização e formalização do trabalho destes trabalhadores junto aos sistemas de coleta de resíduos, nos quais além dos serviços de coleta e triagem, também podem realizar atividades de beneficiamento e comercialização de resíduos sólidos. Embora exista um discurso de reconhecimento do importante papel que essas cooperativas de catadores desempenham, tanto ambiental quanto socialmente, estes empreendimentos passam por diversos problemas, tais como: dificuldade de se inserirem no mercado da reciclagem de resíduos, a exploração econômica, social e política a que os catadores estão submetidos, ausência de políticas para regulação dos preços, entre outros. Zanin e Mônaco (2008) apontam fatores importantes que influenciam na correlação de forças de negociação destas cooperativas ao exercerem sua atividade econômica e que não favorecem os catadores, tais como: a falta de entendimento por parte dos catadores da cadeia produtiva da reciclagem, principalmente no que diz respeito aos atores envolvidos 
e os papéis que eles desempenham na cadeia, a jusante e a montante da atividade dos catadores, o desconhecimento do ambiente dos negócios e das tecnologias existentes, entre outros. Também nos aspectos relacionados às legislações brasileiras existentes, como a Política Nacional de Resíduos Sólidos/2010 e o decreto $\mathrm{n}^{\circ}$ 5.940/2006, buscaram incluir os empreendimentos de catadores na gestão compartilhada dos resíduos sólidos urbanos. No entanto, isso ainda não é suficiente para sua inclusão na cadeia produtiva com valores igualitários aos outros setores ou elos da cadeia produtiva da reciclagem dos resíduos sólidos. É preciso que os municípios e os estados direcionem políticas públicas para promover o fortalecimento desses empreendimentos dentro desta cadeia produtiva, conforme indicam Gutierrez e Zanin (2011b).

O acesso a conhecimentos, tecnologias e políticas públicas é uma condição fundamental não apenas para empreendimentos de economia solidária, mas para todas as formas e estratégias de organização socioeconômica. No entanto, atualmente, esse acesso "é desigual, ou seja, ele reproduz o próprio padrão de desigualdade socioeconômica, com os fundos públicos e as instituições de pesquisa direcionadas, em sua maioria, para atender às demandas de competitividade dos setores empresariais provados pelo sistema capitalista." (SILVA; FARIA, 2009, p. 77).

Baseado nestas considerações, pergunta-se: Estes empreendimentos econômicos solidários de catadores têm acesso ou contato com os processos tecnológicos e equipamentos da cadeia produtiva da reciclagem dos materiais? De que maneira eles lidam com a tecnologia existente? Há apropriação ou adequação às necessidades cotidianas? De que maneira as formas de triagem, acondicionamento, comercialização e outros produtos promovem o avanço na cadeia produtiva? Como estes empreendimentos estão se relacionando com a cadeia produtiva e com os valores da economia solidária? Neste sentido, este trabalho busca identificar aspectos da relação entre as tecnologias existentes e os valores da economia solidária quanto à sua atuação na cadeia produtiva da reciclagem dos resíduos.

\section{Método e procedimentos}

Para desenvolver esse trabalho foi realizada uma pesquisa exploratória em um empreendimento coletivo de catadores de resíduos no município de São Carlos/SP e realizadas atividades de campo. Tais atividades envolveram visitas ao empreendimento, coleta de dados por meio de entrevistas semi-estruturadas para análise quantitativa e qualitativa, e observação direta. Foram entrevistados alguns cooperados, diretores e presidente da cooperativa. 
Também se utilizou a técnica observacional e foi preparado um relatório com informações selecionadas do Sistema Nacional de Informações em Economia Solidária - SIES (BRASIL, 2007) para comparar com o momento atual dos EES (quadro 1). As respostas dessas questões foram sistematizadas e apresentadas em forma de quadros.

A técnica observacional foi utilizada para examinar como os trabalhadores lidam com o processo de triagem, com a organização do trabalho coletivo, quais tecnologias eram utilizadas e de que maneira, e também para identificar o desenvolvimento de Tecnologias Sociais no empreendimento. Os recursos utilizados para o registro das informações em campo foram: gravador, diário de campo e máquina fotográfica.

Para facilitar a análise e categorização do empreendimento em relação ao avanço na cadeia produtiva da reciclagem foi criada uma escala de estágios (quadro 1). Os dados provenientes da identificação das etapas da cadeia de reciclagem de resíduos (triagem e classificação, beneficiamento, reciclagem e transformação), das atividades realizadas e do uso de tecnologias (equipamentos, ferramentas, conhecimentos) foram relacionados a esta escala.

Quadro 1 - Etapas da cadeia de reciclagem de resíduos, tecnologias existentes e grau tecnológico aplicado para analisar o avanço na cadeia produtiva da reciclagem

\begin{tabular}{|c|c|c|c|}
\hline $\begin{array}{l}\text { Etapas da cadeia } \\
\text { de reciclagem de } \\
\text { resíduos }\end{array}$ & Atividades realizadas & $\begin{array}{l}\text { Grau tecnológico } \\
\text { e avanço na } \\
\text { cadeia produtiva }\end{array}$ & $\begin{array}{c}\text { Tecnologia: } \\
\text { Equipamento, } \\
\text { infraestrutura e } \\
\text { conhecimento }\end{array}$ \\
\hline \multirow{2}{*}{ Coleta } & $\begin{array}{l}\text { Coleta realizada porta a } \\
\text { porta, PEVs e grandes } \\
\text { geradores de resíduos }\end{array}$ & Categoria I & $\begin{array}{l}\text { Carrinhos, "bags", } \\
\text { caminhão e outros } \\
\text { recursos }\end{array}$ \\
\hline & $\begin{array}{l}\text { LEVs e grandes geradores } \\
\text { de resíduos }\end{array}$ & Categoria II & $\begin{array}{l}\text { Local para entrega e } \\
\text { caminhão }\end{array}$ \\
\hline \multirow[b]{2}{*}{$\begin{array}{l}\text { Triagem, } \\
\text { classificação e } \\
\text { armazenamento }\end{array}$} & $\begin{array}{l}\text { Separação por tipo: papel, } \\
\text { plástico, vidro, alumínio }\end{array}$ & Categoria I & $\begin{array}{l}\text { - Mesas, esteiras } \\
\text { - Contêineres } \\
\text { - Sacolas “bags" } \\
\text { - Outros }\end{array}$ \\
\hline & $\begin{array}{l}\text { Categorizar dentro de } \\
\text { cada tipo e características } \\
\text { do material: Exemplo 1- } \\
\text { Papel - papelão, papel } \\
\text { branco, sujo, misturado, } \\
\text { jornal } \\
\text { Exemplo } 2 \text { - Plástico - } \\
\text { PET, filme e gerais }\end{array}$ & Categoria II & $\begin{array}{l}\text { - Baias, galpões } \\
\text { - Condições e } \\
\text { procedimentos de } \\
\text { triagem, classificação e } \\
\text { armazenamento. } \\
\text { - Técnicas } \\
\text { - Outros }\end{array}$ \\
\hline
\end{tabular}


Quadro 1 - Etapas da cadeia de reciclagem de resíduos, tecnologias existentes e grau tecnológico aplicado para analisar o avanço na cadeia produtiva da reciclagem

\begin{tabular}{|c|c|c|c|}
\hline \multirow{4}{*}{$\begin{array}{l}\text { Beneficiamento: } \\
\text { prensagem, } \\
\text { moagem, lavagem e } \\
\text { secagem }\end{array}$} & Comprimir o material & Categoria I & Prensa \\
\hline & $\begin{array}{l}\text { Moer ou picar o material } \\
\text { misturado }\end{array}$ & Categoria II & \multirow{3}{*}{$\begin{array}{l}\text { - Moinho, picador, } \\
\text { lavadora, secadora } \\
\text { - Informações } \\
\text { tecnológicas e outras }\end{array}$} \\
\hline & $\begin{array}{l}\text { Moer ou picar material } \\
\text { por tipo ou cor }\end{array}$ & Categoria III & \\
\hline & Deixar o material limpo & Categoria IV & \\
\hline $\begin{array}{l}\text { Reciclagem e } \\
\text { transformação }\end{array}$ & Produzir novos produtos & Categoria I & $\begin{array}{l}\text { - Liquidificador, telas, } \\
\text { formas, forno, extrusora } \\
\text { - Informações } \\
\text { tecnológicas e outras }\end{array}$ \\
\hline
\end{tabular}

\section{Desenvolvimento e fundamentos}

Algumas terminologias utilizadas no desenvolvimento do trabalho são apresentadas neste item para melhor compreensão e análise dos resultados, tais como: economia solidária, cadeia produtiva da reciclagem de resíduos e adequação sóciotécnica.

\section{Economia Solidária}

As iniciativas coletivas em diversas atividades econômicas têm sido criadas no Brasil como uma das formas de luta pela vida. Essas atividades, em seu conjunto, dão suporte à economia solidária que segundo o Fórum Brasileiro de Economia Solidária, é "fruto da organização de trabalhadores e trabalhadoras na construção de novas práticas econômicas e sociais fundadas em relações de colaboração solidária, inspiradas por valores culturais que colocam o ser humano como sujeito e finalidade da atividade econômica, em vez da acumulação privada de riqueza em geral e de capital em particular.” (FBES, 2006, p. 3). Todos os empreendimentos de economia solidária guardam grande semelhança entre si, uma vez que são caracterizados por algum tipo de atividade econômica, pela cooperação, pela solidariedade e pela autogestão. Estas práticas sociais e econômicas além de privilegiarem a propriedade coletiva também beneficiam a justiça social, o cuidado com o meio ambiente e o cuidado com as gerações futuras (BRASIL, 2007).

O tema da Economia Solidária vem sendo pesquisado sistematicamente em diversos países do mundo. $\mathrm{O}$ interesse cada vez maior dos pesquisadores vem demonstrando que estas práticas transcendem o campo das iniciativas isoladas para um complexo desenvolvimento socioeconômico, com o objetivo de compreender a sua 
emergência. É necessário informar que se trata de um movimento recente e seus conceitos foram gestados na segunda metade dos anos 1990, sendo Jean-Louis Laville como trabalho pioneiro na França em 1994, concomitantemente com o pioneiro no Brasil, Paul Singer, que hoje é o atual secretário da primeira Secretaria Nacional de Economia Solidária - SENAES, órgão que compõe o conjunto de secretarias do Ministério do Trabalho e Emprego, criado em 2003 pelo governo Lula (VALENTIM JR; SOBOTTKA, 2010).

\section{A cadeia produtiva da reciclagem de resíduos}

Uma cadeia produtiva pode ser definida como um sistema constituído por agentes formadores de decisão envolvidos em um processo interdependente, por meio de um fluxo de produtos e serviços em uma direção. Pode envolver desde fornecedores de matéria prima, produção propriamente dita, distribuição e até consumidores finais (PADILHA; BOMTEMPO, 1999). Todos os elementos ou níveis de uma cadeia executam funções importantes, cujos respectivos desempenhos determinam de forma interdependente o desempenho do sistema como um todo (AQUINO; CASTILHO Jr.; PIRES, 2009).

$\mathrm{Na}$ cadeia produtiva da reciclagem, algumas terminologias são utilizadas ${ }^{2}$, a saber:

a) catador de material reciclável: segundo a classificação brasileira de ocupações de 2002, o(a) catador(a) de material reciclável é aquele(a) trabalhador(a) que cata, seleciona e vende materiais recicláveis como papel, papelão, plástico e vidro, bem como materiais ferrosos e não ferrosos e outros materiais reaproveitáveis;

b) o empreendimento econômico solidário de catadores: é um empreendimento de catadores organizados com os princípios da Economia Solidária (autogestão, solidariedade, cooperação e atividade econômica) que realiza geralmente a compra e a venda de materiais recicláveis como papel, papelão, plástico e vidro, bem como materiais ferrosos e não ferrosos e outros materiais reaproveitáveis. Fazem a venda de materiais normalmente para os atravessadores. Entre as demais atividades mais desenvolvidas estão: a coleta, a pesagem, a triagem, a prensagem e a armazenagem;

c) intermediário: é uma organização que realiza geralmente a compra e a venda de materiais recicláveis. Entre as atividades desenvolvidas por intermediários estão: a pesagem, a trituração, a prensagem, a armazenagem e o transporte de grande quantidade de materiais. Como intermediário, classificam-se as empresas com fins lucrativos formais e informais. Os intermediários forçam uma relação de

\footnotetext{
${ }^{2}$ Terminologias modificadas a partir de Aquino; Castilho Jr. e Pires (2009).

BRASIL. Ministério do Trabalho e Emprego, Secretaria Nacional de Economia Solidária, Atlas de Economia Solidária no Brasil, Brasília, 2007.
} 
dependência junto aos empreendimentos de catadores e compram os materiais a preços baixos; e

d) indústria recicladora: é o grupo de indústrias que realiza a transformação de material reciclável.

A estrutura da cadeia de reciclagem é piramidal. No topo da pirâmide encontra-se um pequeno número de indústrias de reciclagem. Abaixo, há os intermediários que articulam uma ampla rede de atravessadores desde pequenos sucateiros até grandes cartéis associados a empresas. Na base da pirâmide encontram-se os catadores que atuam majoritariamente por conta própria em lixões ou vias urbanas. As cooperativas e associações de catadores buscam colocar-se no nível médio da pirâmide, mas normalmente não possuem instrumentos de trabalho adequados (ETHOS, 2007). Na ponta ou topo da pirâmide, o valor agregado ao produto é maior.

O grande número de catadores e empreendimentos espalhados pelo Brasil e que forma a base desta pirâmide são os que vendem seus produtos com o menor valor agregado. O entendimento dessa estrutura em forma de pirâmide pode contribuir para testar uma das hipóteses da pesquisa que é: avançar na cadeia produtiva da reciclagem de resíduos agrega valor ao produto e gera maior renda para os empreendimentos de catadores.

\section{Adequação Sóciotécnica}

A proposição da terminologia de Adequação Sóciotécnica, segundo Dagnino (2004), se dá no contexto de reemergência de temas relacionados às tecnologias alternativas dentro de movimentos sociais como o das Redes de Economia Solidária, o das Incubadoras Tecnológicas de Cooperativas Populares (ITCPs), o das cooperativas populares e das fábricas recuperadas.

A proposta de Adequação Sóciotécnica (AST) pode ser compreendida com o auxílio da análise proporcionada pelo construtivismo social da tecnologia em que a Construção Sóciotécnica é o processo pelo qual artefatos tecnológicos vão tendo suas características definidas por meio da negociação entre grupos sociais relevantes, com interesses e preferências diferentes nos quais critérios distintos vão sendo empregados até chegar a um momento de estabilização e fechamento (BIJKER, 1995).

A AST pode ser entendida como:

um processo inverso ao da construção, em que um artefato tecnológico sofreria um processo de adequação aos interesses políticos de grupos sociais relevantes distintos daqueles que o originaram. Definido como 
um processo, e não como um resultado (uma tecnologia desincorporada ou incorporada em algum artefato) a ser obtido tal como concebia o movimento de Tecnologia Apropriada (TA), a AST substitui a idealização típica do laboratório pela prática concreta dos movimentos sociais (NOVAES; DIAS, 2009, p. 44).

A AST é uma proposta de desconstrução e reconstrução (ou reprojetamento) de artefatos tecnológicos indispensáveis ao crescimento e radicalização do movimento associativista e da autogestão. A partir da interlocução com o construtivismo social da tecnologia, a AST rechaça a idéia do determinismo social de que a mudança social possa, por si só, levar à geração de uma tecnologia com ela compatível.

Dessa maneira, a AST pode ser entendida como:

um processo participativo que busca promover, no interior dos empreendimentos da Economia Solidária, um reprojetamento do conhecimento científico e tecnológico (esteja ele já incorporado em equipamentos, insumos e formas de organização da produção, ou ainda sob a forma intangível e mesmo tácita) ao interesses dos atores que deles participam. Ou seja, um processo que leve a uma adequação não apenas aos requisitos e finalidades de caráter técnico-econômico, como até agora tem sido o usual, mas ao conjunto de aspectos de natureza socioeconômica e ambiental que constituem a relação Ciência, Tecnologia e Sociedade (NOVAES; DIAS, 2009, p. 45).

No contexto dos empreendimentos econômicos solidários, a AST teria como objetivo adequar a tecnologia convencional e também conceber alternativas, aplicando critérios complementares aos técnicos e econômicos usuais propondose a aperfeiçoar seu desenvolvimento.

Para operacionalizar o conceito de AST definiram-se - a partir de Dagnino; Brandão e Novaes (2004) - modalidades de AST:

1) Uso: o simples uso de tecnologia antes empregada (no caso de empresas falidas e transformadas em cooperativas) ou a adoção de tecnologia convencional, mas com alteração da forma como se reparte o excedente gerado.

2) Apropriação: a propriedade coletiva dos meios de produção, gerenciais e de concepção dos produtos é condição do processo, sem que exista modificação no uso concreto que dela se faz.

3) Ajuste do processo de trabalho: adaptação da organização do processo de trabalho à forma coletiva dos meios de produção, à autogestão e ao questionamento da divisão técnica do trabalho. 
4) Revitalização ou repotenciamento das máquinas e equipamentos: aumento da vida útil dos equipamentos e maquinários, além de revitalização, ajustes e recondicionamento dos maquinários.

5) Alternativas tecnológicas: é necessária a utilização de tecnologias alternativas à convencional, pois as modalidades anteriores não são suficientes para suprir as demandas de AST pelos empreendimentos econômicos solidários.

6) Incorporação de conhecimento científico-tecnológico existente: resultante do esgotamento da busca por tecnologias alternativas e percepção de que é necessária a incorporação de novos processos produtivos ou meios de produção de conhecimento científico-tecnológico existente.

7) Incorporação de conhecimento cientifico-tecnológico novo: resultante do esgotamento do processo de inovação incremental por causa da inexistência de conhecimento capaz de ser incorporado a processos ou meios de produção que atendam às demandas por AST.

As modalidades apresentadas permitem abarcar uma multiplicidade de situações e contribuir como ferramental teórico para observação da cooperativa que foi estudada.

\section{Resultados}

Neste item são apresentadas algumas informações gerais da cooperativa e seu histórico e uma descrição dos resultados de acordo com as categorias de análise: apoios/parcerias, separação e comercialização dos resíduos e tecnologias existentes e adequação sóciotécnica.

\section{A cooperativa de catadores de resíduos sólidos da cidade de São Carlos/SP/Brasil: breve histórico e informaçôes gerais}

Até fevereiro de 2010, em São Carlos a coleta seletiva solidária era realizada por três cooperativas de catadores de resíduos (formadas em 2002) com parceria da Prefeitura Municipal de São Carlos. A partir de então, em função do programa proposto pela Prefeitura Municipal, em julho de 2009, de revitalização da coleta seletiva, a coleta é realizada por uma única cooperativa resultante do processo de unificação das três cooperativas. Este programa além de implantar diversas mudanças propôs também a união burocrática e física das atividades das três cooperativas. Para atingir este estágio foi realizado um processo participativo das três cooperativas para construção do regimento e do novo estatuto da cooperativa. Portanto, São Carlos possui apenas uma cooperativa de coleta seletiva que em 
janeiro de 2011 (quando se realizou este estudo) possuía 57 cooperados (34 mulheres e 23 homens) que realizam a coleta seletiva em $80 \%$ da cidade. A renda mensal média de seus trabalhadores(as) é de $\mathrm{R} \$ 620,00$ acrescido dos direitos trabalhistas e o fundo coletivo da cooperativa. O quadro 2 contém as informações gerais sobre o empreendimento e o município.

Quadro 2 - Informações gerais sobre o empreendimento econômico solidário analisado

\begin{tabular}{|l|l|}
\hline Número de associados & $57(34$ mulheres e 23 homens) \\
\hline População da cidade & 221.936 \\
\hline Contratação de funcionários & Sim \\
\hline Número de funcionários & 1 contador \\
\hline $\begin{array}{l}\text { Lei municipal para apoiar os } \\
\text { empreendimentos de catadores }\end{array}$ & $\begin{array}{l}\text { Programa de Fomento à Economia Solidária; } \\
\text { Programa Municipal de Coleta Seletiva }\end{array}$ \\
\hline Cesta básica & Não \\
\hline Retirada mensal & Média R $\$ 620,00+$ INSS* + Fundo \\
\hline Abrangência de coleta na cidade & $80 \%$ \\
\hline Sede própria & Não \\
\hline $\begin{array}{l}\text { Espaço suficiente no barracão para } \\
\text { armazenar o material }\end{array}$ & Não \\
\hline Previsão de construção de nova sede & Não \\
\hline
\end{tabular}

* Instituto Nacional do Seguro Social

\section{Parcerias}

A cooperativa realiza a coleta seletiva solidária na cidade com parceria da Prefeitura Municipal da cidade e atualmente possui um contrato de prestação de serviço apresentado pelo programa de revitalização da coleta seletiva implantado pela Coordenadoria Municipal de Meio Ambiente (CMA), Secretaria Municipal de Trabalho, Emprego e Renda (SMTER), Departamento de Apoio a Economia Solidária da Prefeitura Municipal de São Carlos. Esse novo modelo de contrato ${ }^{3}$ prevê que o grupo conveniado passe a receber pagamento mensal pela prestação de serviço de coleta seletiva na proporção ao atendimento de metas estabelecidas pela administração, bem como pelo acréscimo de resíduo coletado e comercializado. Isto significa que a receita do empreendimento, composta pelo resultado da comercialização dos resíduos coletados somado à remuneração dos serviços de coleta e/ou incentivos ao cumprimento de metas, proporcione a viabilidade econômica da cooperativa, ou seja, que os cooperados tenham retirada líquida não inferior ao salário mínimo vigente no Brasil, mais o provisionamento

\footnotetext{
${ }^{3}$ São Carlos, Prefeitura Municipal de. Departamento de Apoio à Economia Solidária (DAES). Programa de Fomento à Economia Solidária; Programa Municipal de Coleta Seletiva. São Carlos, 2009. Apresentado no III Encontro de Formadores e Apoiadores de Empreendimentos de Catadores.
} 
de fundos e regularização tributária e fiscal do empreendimento. Esse contrato previa, em janeiro de 2011, o repasse de 8 mil reais por mês e o pagamento por tonelada comercializada, a cessão da sede com o pagamento da luz e água, 3 prensas, 1 computador, 3 mesas de triagem, três caminhões com motoristas e assessoria técnica. Em contra partida a cooperativa faz a divulgação "boca a boca", ou seja, diretamente com o cidadão e tem o compromisso de realizar a coleta seletiva em toda cidade.

Atualmente a cooperativa possui apoio do Núcleo Multidisciplinar e Integrado de Estudos, Formação e Intervenção em Economia Solidária (NuMI-EcoSol), da UFSCar, anteriormente conhecido como Incubadora Regional de Cooperativas Populares (INCOOP/UFSCar) para implementar, juntamente com Departamento de Apoio à Economia Solidária - DAES da prefeitura, uma Unidade de Beneficiamento de Plástico (UBP) na cooperativa. Esta UBP é composta por um moinho, lavadora e secadora de plástico que podem agregar maior valor ao plástico comercializado. Foram realizadas oficinas participativas para a formação de alguns cooperados(as) em identificação e triagem dos plásticos, bem como estudos de viabilidade e outros. Esta entidade também realizou em parceria com o DAES um plano estratégico coletivo para o processo de unificação das três cooperativas. A cooperativa recebeu o apoio do departamento de Engenharia de Produção da UFSCar (Programa de Educação Tutorial - PET) para um estudo sobre o "layout" (organização do espaço interno da sede) e para estudo, juntamente com o NuMI-EcoSol/UFSCar, sobre redes de cooperação entre empreendimentos econômicos solidários na cidade de São Carlos.

A cooperativa também foi apoiada pela UNISOL Brasil (Central de Cooperativas e Empreendimentos Solidários) que realiza cursos de capacitação em gestão de empreendimentos, autogestão e outros.

A cooperativa elaborou e encaminhou juntamente com o DAES, INCOOP e UNISOL um projeto que foi aprovado pela Fundação Nacional de Saúde (FUNASA) em 2010. Este projeto prevê 200 mil reais para aquisição de equipamentos para a cooperativa. Os equipamentos solicitados foram: duas balanças eletromecânicas, 2 prensas enfardadeiras verticais, 1 prensa enfardadeira horizontal, 2 empilhadeiras semi-elétricas, 2 mesas de triagem, 1 esteira de triagem com funil de alimentação, 2 carrinhos de tambores, 50 carrinhos de coleta seletiva e 2 motos triciclos urbanos com bagageiro. Em entrevista, foi afirmado que a aprovação deste projeto contribui para a autonomia e consolidação da cooperativa, já que os novos equipamentos serão adquiridos pela própria cooperativa e serão de sua propriedade. Este contribui para ampliar as garantias de que os trabalhadores e trabalhadoras tenham posse dos próprios meios de produção. 


\section{Separação e comercialização dos resíduos e tecnologias existentes}

Atualmente o espaço do barracão (local de funcionamento das atividades da cooperativa), segundo afirmação dos entrevistados, é suficiente para a quantidade de resíduos coletados. Mas, com as metas de expansão determinadas pelo contrato, dentro em breve não haverá espaço para a triagem e o armazenamento dos resíduos. Portanto, necessitam de infra-estrutura para ampliar a coleta seletiva prevista no contrato. Possuem 3 computadores (um cedido pela prefeitura e dois comprados pela cooperativa) e buscam, na internet e em outras fontes, informações sobre o valor dos resíduos no mercado. Assim conseguem estabelecer melhores preços nas transações comerciais com atravessadores. Também possuem uma diversidade de compradores o que possibilita a melhor venda de seus resíduos. Por outro lado, não conseguem reunir um volume muito grande de resíduos porque não possuem espaço suficiente para armazená-los. $\mathrm{O}$ quadro 3 apresenta os equipamentos/tecnologias existentes na cooperativa.

Quadro 3 - Equipamentos/tecnologias existentes no empreendimento

\begin{tabular}{|l|l|}
\hline Computador & 3 computadores (2 da cooperativa e um da prefeitura) \\
\hline Impressora & 2 (uma doada e outra comprada pela cooperativa) \\
\hline Acesso a internet & Sim \\
\hline Telefone & Sim \\
\hline Prensa & $\begin{array}{l}\text { 5 prensas (3 cedidas pela prefeitura, 1 doada pela } \\
\text { universidade e 1 doada por indústria de papelão), apenas 2 } \\
\text { em funcionando no momento }\end{array}$ \\
\hline Manutenção da prensa & Não \\
\hline Caminhão & 3 da prefeitura \\
\hline Manutenção do caminhão & A prefeitura faz \\
\hline Carrinho de mão & Não \\
\hline Alarme anti-furto & Sim \\
\hline Picador de papel & Sim \\
\hline Balança & Sim, mas com pouco uso \\
\hline $\begin{array}{l}\text { Unidade de beneficiamento de } \\
\text { plástico }\end{array}$ & Sim \\
\hline Picador de papel & Sim \\
\hline Empilhadeira & Sim \\
\hline
\end{tabular}

Em relação às categorias estabelecidas para identificar o grau tecnológico da cooperativa, pode-se afirmar que esta desenvolve atividades até o beneficiamento dos resíduos com a utilização de um picador de papel. O quadro 4 contém a síntese das etapas da cadeia de reciclagem de resíduos, grau tecnológico e avanço na cadeia produtiva da reciclagem e exemplos de algumas tecnologias envolvidas e as atividades realizadas na cooperativa de São Carlos. 
Quadro 4 - Síntese das etapas da cadeia de reciclagem de resíduos, grau tecnológico e avanço na cadeia produtiva da reciclagem e exemplos de algumas tecnologias envolvidas e atividades realizadas pela cooperativa de São Carlos

\begin{tabular}{|c|c|c|c|c|}
\hline $\begin{array}{l}\text { Etapas da cadeia } \\
\text { de reciclagem de } \\
\text { resíduos }\end{array}$ & $\begin{array}{l}\text { Atividades } \\
\text { realizadas }\end{array}$ & $\begin{array}{c}\text { Grau } \\
\text { tecnológico e } \\
\text { avanço na } \\
\text { cadeia } \\
\text { produtiva }\end{array}$ & $\begin{array}{l}\text { Tecnologia: } \\
\text { Equipamento, } \\
\text { infra-estrutura e } \\
\text { conhecimento }\end{array}$ & Observação \\
\hline Coleta & $\begin{array}{l}\text { Coleta realizada } \\
\text { porta a porta }\end{array}$ & Categoria I & $\begin{array}{l}\text { “Bags", caminhão e } \\
\text { material de } \\
\text { divulgação }\end{array}$ & \\
\hline $\begin{array}{l}\text { Triagem, } \\
\text { classificação e } \\
\text { armazenamento }\end{array}$ & $\begin{array}{l}\text { Categorizar } \\
\text { dentro de cada } \\
\text { tipo e caracterís- } \\
\text { ticas do material: } \\
\text { Exemplo 1- } \\
\text { Papel - papelão, } \\
\text { papel branco, } \\
\text { sujo, misturado, } \\
\text { jornal } \\
\text { Exemplo 2- } \\
\text { Plástico - PET, } \\
\text { filme e gerais }\end{array}$ & Categoria II & $\begin{array}{l}\text {-“Bags”, mesas } \\
\text { - Condições e } \\
\text { procedimentos de } \\
\text { triagem } \\
\text { - Classificação e } \\
\text { armazenamento } \\
\text { - Técnicas }\end{array}$ & \\
\hline \multirow[b]{2}{*}{$\begin{array}{l}\text { Beneficiamento: } \\
\text { prensagem, } \\
\text { moagem, lavagem e } \\
\text { secagem }\end{array}$} & $\begin{array}{l}\text { Comprimir o } \\
\text { material }\end{array}$ & Categoria I & Prensa & \\
\hline & $\begin{array}{l}\text { Moer ou picar o } \\
\text { material } \\
\text { misturado }\end{array}$ & Categoria II & $\begin{array}{l}\text { Picador e } \\
\text { conhecimento } \\
\text { necessário para o } \\
\text { manunseio }\end{array}$ & $\begin{array}{l}\text { - Utilizam } \\
\text { picador de papel } \\
\text { - Possuem } \\
\text { moinho, lavadora } \\
\text { e secadora de } \\
\text { plástico, mas não } \\
\text { são utilizados }\end{array}$ \\
\hline
\end{tabular}

A cooperativa possui as tecnologias necessárias para a coleta, triagem, prensagem, comercialização e moagem dos resíduos. Para a coleta seletiva a cooperativa dispõe de 3 caminhões cedidos pela prefeitura e bags para o armazenamento. Os caminhões ficam estacionados em pontos de apoio de cada setor aguardando os cooperados a levarem o resíduo recolhido (até esgotar a capacidade do bau do caminhão) e posteriormente este é levado para pesagem em uma empresa privada que empresta a balança para o uso da cooperativa.

A triagem dos diferentes resíduos é realizada em mesas, estes são armazenados em bags para posterior prensagem. O conhecimento necessário para a identificação dos diferentes resíduos é passado entre os cooperados(as). No quadro 5, são apresentadas as categorias de separação dos resíduos, conforme os processos de triagem realizados pela cooperativa. 
Quadro 5 - Categorias de separação dos resíduos realizada pela cooperativa

\begin{tabular}{|l|l|l|l|l|}
\hline \multicolumn{1}{|c|}{ Papel } & \multicolumn{1}{|c|}{ Metal } & \multicolumn{1}{c|}{ Plástico } & \multicolumn{1}{c|}{ Vidro } & \multicolumn{1}{c|}{ Outros } \\
\hline Tetra Pak & Alumínio Lata & PP & $\begin{array}{l}\text { Avulso (por } \\
\text { unidade) }\end{array}$ & Óleo \\
\hline Papelão & Bateria & PS & Moído incolor & - \\
\hline Papelão Terceira & $\begin{array}{l}\text { Cobre } \\
\text { Antimonio }\end{array}$ & PEAD branco & $\begin{array}{l}\text { Moído escuro } \\
\text { (verde e } \\
\text { marrom) }\end{array}$ & - \\
\hline Papel colorido & Chumbo & PEAD colorido & - & - \\
\hline $\begin{array}{l}\text { Papel Branco } \\
\text { (arquivo) }\end{array}$ & Metal & PET verde & - & - \\
\hline Jornal amarrado & Tubinho Cavaco & $\begin{array}{l}\text { PET } \\
\text { transparente }\end{array}$ & - & - \\
\hline- & Sucata & PET azul & - & - \\
\hline
\end{tabular}

Para a prensagem dos resíduos a cooperativa conta com cinco prensas ( 3 cedidas pela prefeitura, 1 doada pela universidade e 1 doada pela indústria de papelão), sendo que apenas duas encontram-se em condições de uso, e uma empilhadeira para organizar os resíduos já prensados. Dispõe também de tecnologia para picar papel, doação feita pela prefeitura, no momento indisponível para uso. A cooperativa tem, ainda, tecnologia para triturar, lavar e secar o plástico, que não está totalmente instalada. No quadro 6 são apresentadas informações sobre quantidade de resíduos coletado, rejeitos, material separado e sua comercialização.

Quadro 6 - Informações sobre os materiais coletados e sua comercialização
\begin{tabular}{|l|l|}
\hline Quantidade de resíduos coletados (ton.) & 115 \\
\hline Rejeito (\%) & 20 \\
\hline Material separado e prensado (\%) & 100 \\
\hline Vende para atravessador & Sim \\
\hline Possui diferentes compradores & Sim \\
\hline Número de compradores & Mais de 15 \\
\hline Vende para a indústria & Sim (papelão, PET e plástico) \\
\hline
\end{tabular}

\section{Adequação Sóciotécnica}

O uso das tecnologias convencionais e a forma igualitária como é repartido o excedente gerado foram observados na pesquisa de campo. Os sócios se apropriaram das tecnologias existentes e tem a propriedade coletiva dos meios de produção e gerenciais da cooperativa. Dentro da cooperativa não há divisão técnica do trabalho, já que todos os sócios devem aprender e são capazes de exercer as diferentes atividades dentro da cooperativa. Os conhecimentos necessários para o desenvolvimento das atividades são transmitidos entre os 
cooperados. Essas atividades técnicas são: coleta na rua; divulgação; primeira separação dos resíduos na mesa; separação especializada dos diferentes resíduos (por exemplo, separação dos plásticos: diferentes tipos e cores e resíduos elétricoeletrônicos: uma pessoa só para fazer essa atividade); prensagem; enfardamento; administração.

A administração da cooperativa é feita por cooperados. Os cooperados que atuam na administração são definidos pelos próprios cooperados (as) em um processo coletivo de decisão. Os conhecimentos necessários para administrar a cooperativa e utilizar as tecnologias específicas são transmitidos pelos cooperados que já estão a mais tempo na atividade. Dessa maneira, o ajuste do processo de trabalho à forma coletiva dos meios de produção e à autogestão é identificado nesta cooperativa.

Como pode ser observado no quadro 7 , esta cooperativa apresenta apenas três das sete modalidades definidas para operacionalisar o conceito de adequação sociotécnica.

\begin{tabular}{|} 
Quadro 7 - Modalidades da Adequação Sóciotécnica observadas na cooperativa \\
\hline Modalidades & Presença \\
\hline Uso & Sim \\
\hline Apropriação & Sim \\
\hline Ajuste do processo do trabalho & Sim \\
\hline Revitalização ou repotenciamento das máquinas e equipamentos & Não \\
\hline Alternativas tecnológicas & Não \\
\hline Incorporação de conhecimento científico-tecnológico existente & Não \\
\hline Incorporação de conhecimento cientifico-tecnológico novo & Não \\
\hline
\end{tabular}

\section{Discussão geral e conclusões}

Segundo os resultados apresentados, a cooperativa de catadores de resíduos da cidade de São Carlos não possui sede própria, seu espaço de trabalho é cedido pela prefeitura municipal e não é suficiente para armazenar todos os resíduos coletados e triados. Este resultado está de acordo com os resultados obtidos em estudo semelhante referente aos empreendimentos de catadores do Estado de São Paulo (GUTIERREZ; ZANIN, 2011a), no qual se observou que apenas 3\% dos 115 empreendimentos de catadores analisados no estudo possuem sede própria, enquanto a grande maioria $(79 \%)$ dos empreendimentos possuem sedes cedidas ou emprestadas. A falta de espaço para a triagem e armazenamento dos resíduos é um fator limitante para que o empreendimento possa comercializar seus resíduos a um preço melhor. Pois para fazerem melhores negócios e conquistar valores mais altos para os resíduos é preciso ter um grande volume de materiais. Dessa forma, como o empreendimento não pode acumular muito material, os cooperados são obrigados a comercializar seus resíduos de forma semanal ou no máximo 
quinzenalmente. Isso também acarreta na diminuição da possibilidade de venderem diretamente para as indústrias que, geralmente, exigem grandes volumes de resíduos.

A falta de sede própria, bem como os equipamentos que são cedidos para uso da cooperativa, foram apontados como um entrave que gera insegurança. O contrato firmado com a prefeitura, embora seja um avanço em termos de reconhecimento do trabalho realizado também gera preocupações, pois se a parceria for interrompida (quer seja por mudança de governo ou outro interesse da prefeitura) o empreendimento pode ser obrigado a sair do espaço físico em que se encontra. Isso exprime que mesmo que os catadores consigam controlar o processo de produção, conheçam todas as etapas do trabalho realizado dentro da cooperativa, ajudem a organizar o trabalho, conheçam os atores da cadeia produtiva da reciclagem, sejam donos do produto de seu trabalho e socializem seu saber, eles ainda não são donos dos meios físicos de produção. O fato de não serem donos dos meios físicos de produção significa que esses catadores continuarão na situação de dependência em relação aos órgãos públicos. Quanto aos aspectos da economia solidária, a propriedade dos meios de produção é considerada fator determinante para que os empreendimentos exerçam as atividades com maior autonomia.

$\mathrm{O}$ acesso às tecnologias e à infra-estrutura é condição fundamental para o desenvolvimento do trabalho realizado pelos empreendimentos econômicos solidários de catadores. O computador com a internet é uma tecnologia que se mostrou determinante para a busca por informações referentes à comercialização de resíduos. A prensa é outra tecnologia imprescindível para uma melhor comercialização dos resíduos. Observou-se que esta cooperativa possui tecnologias de beneficiamento dos resíduos para além da triagem e prensagem (no caso picador de papel e unidade de beneficiamento de plástico), embora no momento em desuso.

Dessa forma, avançar na cadeia produtiva não significa necessariamente possuir tecnologias para beneficiar os resíduos para além da triagem e prensagem. No caso da cooperativa analisada, o acesso ao conhecimento do mercado dos resíduos e a capacidade da cooperativa em negociar os produtos, a especialização na triagem dos resíduos, a venda direta para a indústria sem a figura do atravessador, a quantidade de resíduos comercializados e o acesso às tecnologias para a coleta, triagem, prensagem e comercialização dos resíduos são fatores que determinam o seu avanço na cadeia produtiva da reciclagem dos resíduos. $\mathrm{O}$ acesso diferenciado à infraestrutura como barracão, caminhões e tecnologias para beneficiamentos dos resíduos e a qualificação profissional foi alcançado por meio dos apoios e parcerias estabelecidas com a prefeitura. Portanto, o investimento do governo municipal para a existência e manutenção deste empreendimento é fundamental, pois este ainda não possui condições financeiras para adquirir toda a infraestrutura necessária para ser detentor dos meios físicos de produção. 
Observou-se que a cooperativa estudada exerce a autogestão e reparte o excedente gerado. Os cooperados(as) fazem uso das tecnologias convencionais (esteiras, prensas, computadores, telefones, carrinhos de carga e outros), mas alteram a forma como repartem o excedente gerado. Todos os sócios fazem a retirada de forma igualitária. Os cooperados desta cooperativa se apropriaram das tecnologias existentes, e têm a propriedade coletiva dos meios de produção e gerenciais da cooperativa. Foi observado que não há divisão técnica do trabalho, já que todos os sócios devem aprender e são capazes de exercer as diferentes atividades dentro da cooperativa. Os conhecimentos necessários para o desenvolvimento das atividades são transmitidos entre os cooperados. Não foi possivel observar neste empreendimento a busca por alternativas tecnológicas para suprir as necessidades do seu cotidiano e nem revitalização ou repotenciamento das máquinas e equipamentos ou incorporação de conhecimento científico-tecnológico. No entanto, é possível identificar um reprojetamento do conhecimento científico e tecnológico já incorporado nos processos de separação dos resíduos e na forma de organização da produção aos interesses dos catadores e concluir que a tecnologia social, instrumentalizada pelo conceito da Adequação Sóciotécnica, pode ser observada no empreendimento (quando adequa a tecnologia convencional à realidade dos cooperados).

Assim, a forma como os catadores se relacionam com a tecnologia é um fator relevante, pois no modo de produção capitalista a tecnologia reproduz os valores do capital, ou seja, é poupadora de mão-de-obra, segmentada, hierarquizada e alienante. A tecnologia utilizada pelos catadores poderia ser entendida como tecnologia capitalista ou tecnologia convencional (já que utilizam tecnologias para empresas capitalistas), mas esses empreendimentos possuem em seus princípios outros valores que não o do capital. Os empreendimentos econômicos solidários compartilham a solidariedade, autogestão e cooperação, portanto os valores reprojetados nas tecnologias utilizadas não são valores da tecnologia convencional. Dessa forma, os catadores buscam adequar essa tecnologia convencional para as suas próprias realidades e necessidades.

Agradecimentos: As autoras agradecem a FAPESP pelo apoio financeiro, aos cooperados e cooperadas que contribuíram com a pesquisa e a Fátima Cruz Souza pelo apoio na tradução. 


\section{Referências}

AQUINO, I. F.; CASTILHO Jr., A. B.; PIRES, T. S. L. A organização em rede dos catadores de materiais recicláveis na cadeia produtiva reversa de pós-consumo da região da grande Florianópolis: uma alternativa de agregação de valor. Gestão \& Produção, São Carlos, v. 16, n. 1, p.15-24, 2009.

BIJKER, W. E. Of bicycles, bakelites, and bulbs: toward a theory of sociotechnical change. Massachusetts: MIT Press, 1995.

BRASIL. Ministério do Trabalho e Emprego. Atlas de Economia Solidária no Brasil, Brasília: Secretaria Nacional de Economia Solidária, 2007.

DAGNINO, R. A. tecnologia social e seus desafios. In: Tecnologia social: uma estratégia para o desenvolvimento. Rio de Janeiro: Fundação Banco do Brasil, 2004.

DAGNINO, R.; BRANDÃO, F. C.; NOVAES, H. T. Sobre o marco analíticoconceitual da tecnologia social. In: Tecnologia Social: uma estratégia para o desenvolvimento. Rio de Janeiro: Fundação Banco do Brasil, 2004. p. 15-64.

FBES. A experiência de gestão e organização do Movimento de Economia Solidária no Brasil. Brasília: Fórum Brasileiro de Economia Solidária, 2006.

GUTIERREZ, R.F; ZANIN, M. Empreendimentos econômicos solidários de catadores do Estado de São Paulo: Um panorama a partir do Sistema Nacional de Informação em Economia Solidária. Revista Pegada Eletrônica (Online). Especial, p. 94-111, 2011a.

- Empreendimentos econômicos de catadores de resíduos e legislações vigentes: avanços e limites. Revista Interinstitucional de Psicologia, 4 (2), Edição Especial, p. 113-121, dez., 2011 b.

ETHOS. Instituto Ethos de Empresas e Responsabilidade Social. Vínculos de negócios sustentáveis em resíduos sólidos. São Paulo, 2007. Disponível em: $<$ http://www.ethos.org.br/_Uniethos/documents/VincSust_res_sold_A4.pdf >

NOVAES, Henrique T.; DIAS, Rafael. Contribuições ao marco analíticoconceitual da tecnologia social. In: DAGNINO, R. (Org.). Tecnologia social: ferramenta para construir outra sociedade. Campinas: IG/UNICAMP, 2009. p. 17-53. 
PADILHA, G. M. A.; BOMTEMPO, J. V. A inserção dos transformadores de plásticos na cadeia produtiva de produtos plásticos. Revista Polímeros: Ciência e Tecnologia, 1999.

SILVA, R. M. A. da; FARIA, M. S. de. Tecnologias sociais e economia solidária: diretrizes, desafios e perspectivas para políticas públicas. In: BOCAYUVA, P. C.C.; VARANDA, A. P. de M. (Orgs.) Tecnologia social, economia solidária e políticas públicas. Rio de Janeiro: FASE, 2009.

VALENTIM Jr, S. L.; SOBOTTKA, E. A. O movimento da economia solidária: a emergência de um movimento social pela humanidade. Disponível em: <http://www.pucrs.br/edipucrs/online/IIImostra/CienciasSociais/62827 \%20-\%20SERGIO\%20LUIZ\%20VALENTIM\%20JUNIOR.pdf>. Acesso em: 10 out. 2010.

ZANIN, M.; MÔNACO, G. Cooperativas de catadores e o acesso ao conhecimento e inovações tecnológicas. In: HOFFMANN, W.; FURNIVAL, A. (Orgs.). Olhar: ciência, tecnologia e sociedade. São Paulo: Pedro e João Editores, 2008.

Endereços para correspondência:

Rafaela Francisconi Gutierrez_rafaela_fg@yahoo.com.br Cidade Universitária Zeferino Vaz, Instituto de Geociências 13083-970 Campinas/SP, Brasil

MariaZanin-dmza@ufscar.br Rod. Washington Luís, km 235 13565-905 São Carlos, SP, Brasil 